\title{
The Phenotype of Patients with a Recent Fracture: A Literature Survey of the Fracture Liaison Service
}

\author{
Lisanne Vranken ${ }^{1,2}$ (1) Caroline E. Wyers ${ }^{1,2}$ Joop P. W. van den Bergh ${ }^{1,2,3}$. \\ Piet P. M. M. Geusens ${ }^{3,4}$
}

Received: 18 January 2017/ Accepted: 21 April 2017/Published online: 24 May 2017

(C) The Author(s) 2017. This article is an open access publication

\begin{abstract}
The aetiology of fractures in patients aged 50 years and older is multifactorial, and includes bone- and fall-related risks. The Fracture Liaison Service (FLS) is recommended to identify patients with a recent fracture and to evaluate their subsequent fracture risk, in order to take measures to decrease the risk of subsequent fractures in patients with a high risk phenotype. A literature survey was conducted to describe components of the bone- and fallrelated phenotype of patients attending the FLS. Components of the patient phenotype at the FLS have been reported in 33 studies. Patient selection varied widely in terms of patient identification, selection, and FLS attendance. Consequently, there was a high variability in FLS patient characteristics, such as mean age (64-80 years), proportion of men (13-30\%), and fracture locations (2-51\% hip, <1-41\% vertebral, and 49-95\% non-hip, nonvertebral fractures). The studies also varied in the risk
\end{abstract}

Lisanne Vranken

1.vranken@maastrichtuniversity.nl

1 Department of Internal Medicine, VieCuri Medical Centre, P.O. Box 1926, 5900 BX Venlo, The Netherlands

2 Department of Internal Medicine, NUTRIM School of Nutrition and Translational Research in Metabolism, Maastricht University Medical Centre+ (MUMC+), P.O. Box 616, 6200 MD Maastricht, The Netherlands

3 Biomedical Research Centre, Hasselt University, Agoralaan, Gebouw D, 3590 Diepenbeek, Belgium

4 Department of Internal Medicine, Subdivision Rheumatology, CAPHRI, Maastricht University Medical Centre+ (MUMC+), P.O. Box 616, 6200 MD Maastricht, The Netherlands evaluation performed. When reported, there was a highly variability in the percentage of patients with osteoporosis (12-54\%), prevalent vertebral fractures (20-57\%), newly diagnosed contributors to secondary osteoporosis and metabolic bone disorders (3-70\%), and fall-related risk factors (60-84\%). In FLS literature, we found a high variability in patient selection and risk evaluation, resulting in a highly variable phenotype. In order to specify the bone- and fall related phenotypes at the FLS, systematic studies on the presence and combinations of these risks are needed.

Keywords Fracture Liaison Service - Fractures ·

Secondary prevention $\cdot$ Phenotype

\section{Introduction}

Fractures constitute a major health care concern worldwide, as $50 \%$ of women and $20 \%$ of men at the age of 50 years will sustain a fracture during their remaining lifetime [1,2]. Since the world population is ageing, the annual number of fractures is expected to increase from 3.5 million in 2010 to 4.5 million in 2025 , corresponding to an increase of $28 \%$ [3].

Fractures indicate an increased risk of subsequent fractures and premature mortality [4-7]. Current guidelines recommend secondary fracture risk evaluation in all men and women aged 50 years and older with a recent clinical fracture [8-11]. However, many fracture patients were not offered appropriate secondary fracture prevention, resulting in a care gap throughout the world [12].

Fracture Liaison Services (FLS) have been designed and implemented to diminish the care gap [13]. The key components and objectives of a FLS are multiple. Firstly, 
case finding by systematic identification and selection of fracture patients. Second, to adequately evaluate subsequent fracture risk using clinical risk factors for fractures and falls, dual-energy X-ray absorptiometry (DXA) and imaging of the spine for detection of previously unknown vertebral fractures. Third, analysis for eventual underlying secondary osteoporosis and metabolic bone disorders. Fourth, adequate treatment in patients at high risk, and fifth, development of a follow-up program [14].

Unfortunately, FLS are currently established in a small proportion of facilities that receive fracture patients worldwide [15]. The International Osteoporosis Foundation (IOF), American Society for Bone and Mineral Research (ASBMR), European League Against Rheumatism (EULAR), and European Federation of National Associations of Orthopaedics and Traumatology (EFORT) support the implementation of FLS as they identify this as the most successful approach for secondary fracture prevention [11, 15-18]. In this literature survey, we investigate what has been published on components of the bone- and fallrelated risk factor phenotype in patient attending the FLS.

\section{Methods}

A literature search was conducted in PubMed/Medline, EMBASE and CINAHL to identify relevant publications up to and including October 2016 using the following search terms: Fracture Liaison Service, fracture prevention service, fracture prevention clinic, fracture prevention program, osteoporosis clinic, and secondary fracture prevention. The search was limited to human studies in adults (18-64 years) and aged ( $\geq 65$ years) written in English. We specifically selected articles which reported components of the phenotype of patients at the FLS. Finally, additional relevant publications known to us were added.

\section{Results}

\section{Search Results}

After removing duplicates, our search resulted in 373 potentially relevant publications. Based on title and abstract screening, 270 publications were excluded. Based on full-text eligibility assessment, 80 publications were excluded, resulting in 23 being selected. The reasons for exclusion were no FLS population $(n=40)$, and no components of the phenotype reported $(n=40)$. In addition, manual searches through the reference lists were performed, resulting in 10 additional publications. In total, 33 publications were included in this literature review (Table 1).

\section{Patient Selection Procedure}

The patient selection procedure can comprise up to three steps: (1) the identification and selection of patients with a recent clinical fracture for evaluation at the FLS, (2) the patients' response to the FLS invitation (i.e. the proportion of patients willing and able to attend the FLS), and optionally (3) the selection of a subgroup of FLS attenders to be included in the publication.

\section{Identification and Selection of Patients for Evaluation at the FLS}

Patient identification and selection differed markedly across studies (Table 1 and Fig. 1). Twenty-nine studies identified and selected in- and outpatients [13, 19-46], two studies selected only inpatients $[47,48]$, and two did not report this aspect of patient identification and selection [49, 50]. With respect to age, 26 studies identified and selected patients age 50 years or older $[13,19-42,48]$. Five studies used other age criteria, namely patients aged 45 years and older [43, 49], patients aged 75 years and older [44], or those who were postmenopausal $[45,46]$. In two studies, no age criterion was used $[47,50]$. Thirty-one studies identified and selected both men and women [13, 19-44, 47-50], whereas two studies selected only postmenopausal women $[45,46]$. Patients with any fracture were identified and selected in 31 studies $[13,19-41,43-47,49,50]$, whereas only patients with a nonvertebral fracture were selected in two studies [42, 48].

Various additional exclustion criteria were used, such as high energy trauma fractures, pathological fractures and cognitive impairment. The total number of patients identified and selected for evaluation at the FLS was reported in $18(55 \%)$ of 33 studies (Fig. 1) [13, 19-25, 30, 33-36, 38, 43, 44, 47, 49], and ranged from 156 to 3057 patients (Table 1).

\section{Attendance}

Selected patients were informed personally or through an information letter, except for the study by Fraser et al. [21], in which a letter was sent to the general practitioner informing them of the fragility fracture and invited referral to the fracture prevention clinic. In 17 (52\%) of the 33 studies (Fig. 1), 20-89\% of the patients selected for evaluation at the FLS actually attended the FLS (Table 1 and Fig. 2) [19-25, 30, 33-36, 38, 43, 44, 47, 49].

\section{FLS Attenders Included in the Publication}

Of the 33 studies, 16 (48\%) included all FLS attenders [13, 19-29, 42-45], whereas 17 (52\%) included a subgroup of the attenders (Fig. 1): patients aged $<75$ years [46], patients aged 65 years or older [37], patients diagnosed 


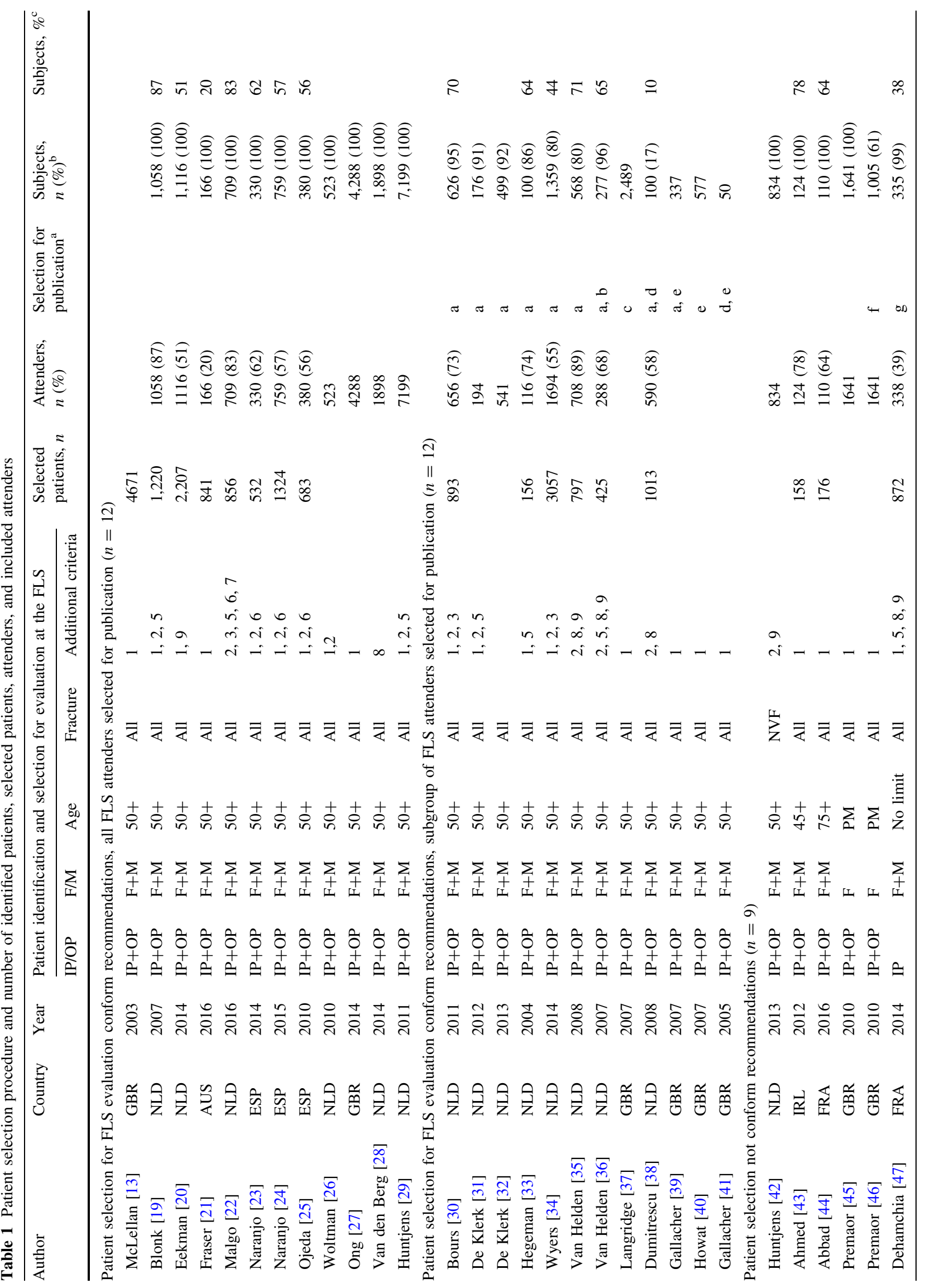



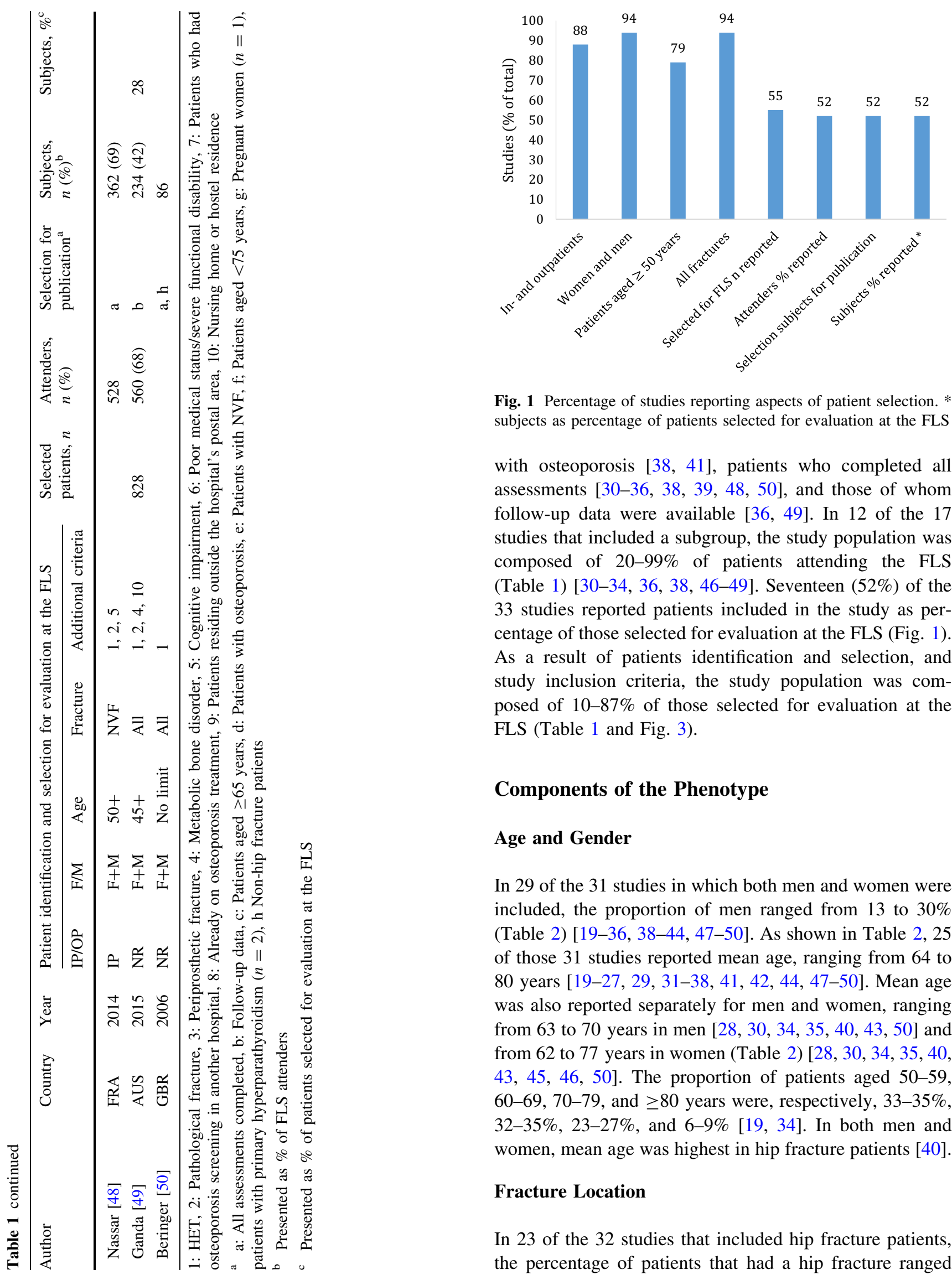

Fig. 1 Percentage of studies reporting aspects of patient selection. * subjects as percentage of patients selected for evaluation at the FLS

with osteoporosis [38, 41], patients who completed all assessments [30-36, 38, 39, 48, 50], and those of whom follow-up data were available [36, 49]. In 12 of the 17 studies that included a subgroup, the study population was composed of $20-99 \%$ of patients attending the FLS (Table 1) [30-34, 36, 38, 46-49]. Seventeen (52\%) of the 33 studies reported patients included in the study as percentage of those selected for evaluation at the FLS (Fig. 1). As a result of patients identification and selection, and study inclusion criteria, the study population was composed of $10-87 \%$ of those selected for evaluation at the FLS (Table 1 and Fig. 3).

\section{Components of the Phenotype}

\section{Age and Gender}

In 29 of the 31 studies in which both men and women were included, the proportion of men ranged from 13 to $30 \%$ (Table 2) [19-36, 38-44, 47-50]. As shown in Table 2, 25 of those 31 studies reported mean age, ranging from 64 to 80 years [19-27, 29, 31-38, 41, 42, 44, 47-50]. Mean age was also reported separately for men and women, ranging from 63 to 70 years in men $[28,30,34,35,40,43,50]$ and from 62 to 77 years in women (Table 2) [28, 30, 34, 35, 40, $43,45,46,50]$. The proportion of patients aged 50-59, $60-69,70-79$, and $\geq 80$ years were, respectively, $33-35 \%$, $32-35 \%, 23-27 \%$, and $6-9 \%[19,34]$. In both men and women, mean age was highest in hip fracture patients [40].

\section{Fracture Location}

In 23 of the 32 studies that included hip fracture patients, the percentage of patients that had a hip fracture ranged 
Fig. 2 Patients attending the FLS as percentage of patients selected for evaluation at the FLS, reported in 17 studies
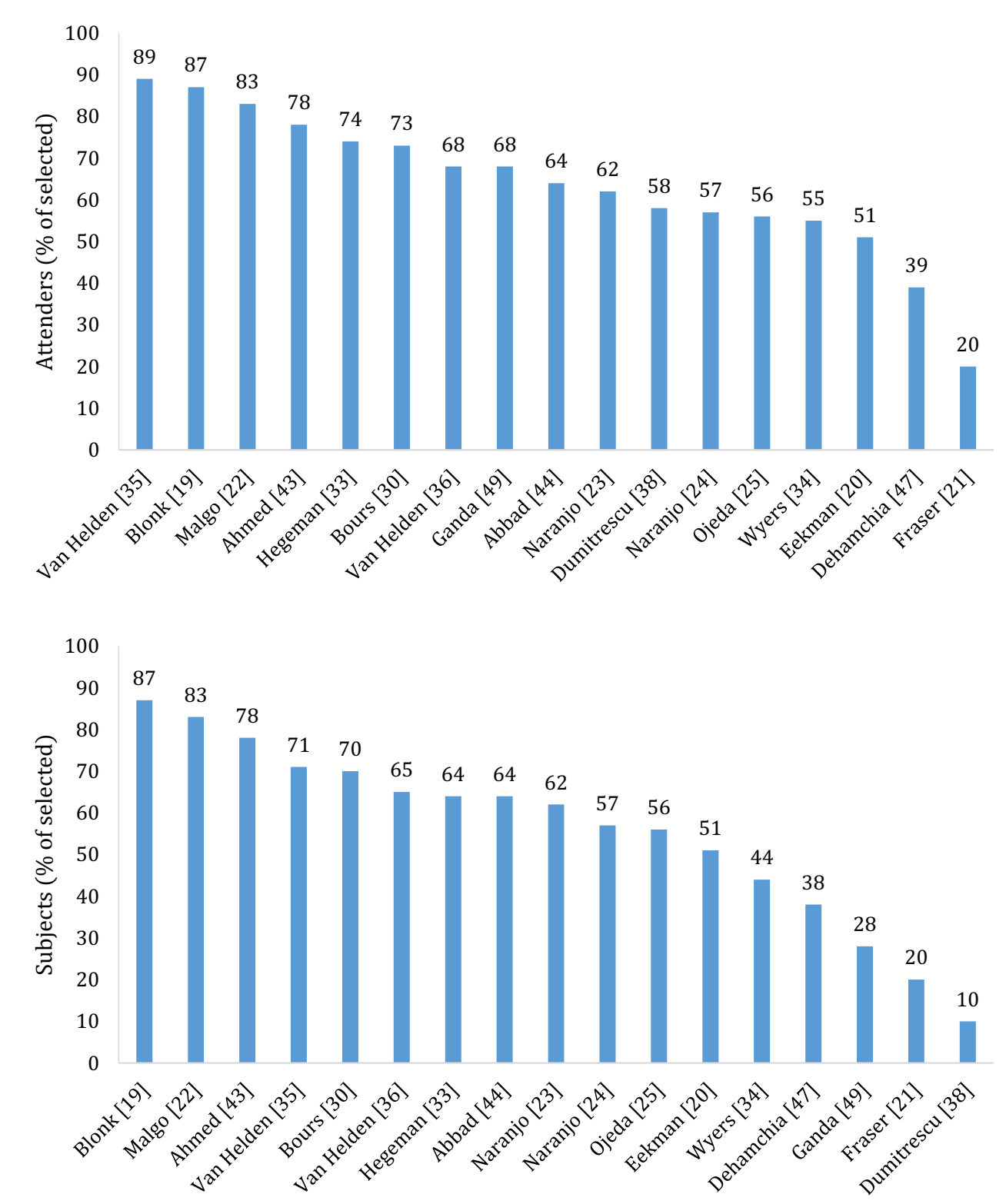

Fig. 3 Patients selected for publication (subjects) as percentage of patients selected for evaluation at the FLS, reported in 17 studies from 2 to $51 \%$ (Table 2) [19, 21-26, 29, 31, 33-35, 37-41, 43-48]. In 14 of the 28 studies that included patients with a clinical vertebral fracture, the percentage of patients with this fracture was reported, ranging from $<1$ to $41 \%$ (Table 2) [19, 21-23, 25, 26, 31, 33, 35, 38, 43, 45, 46, 50]. Most common were non-vertebral, non-hip (NVNH) fractures, of which the prevalence was reported in 18 of the 33 studies, ranging from 49 to $95 \%$ (Table 2) [19, 21-23, 25, 26, 31, 33, 35, 38-41, 43, 45, 46, 48, 50]. Distal radius/ulna fractures were reported as the most common NVNH fracture $(27-32 \%)[13,22,39,47]$, followed by humeral fractures $(11-31 \%)[13,22,39,47]$, ankle fractures $(11-16 \%)[13,22,39,47]$, and hand and foot fractures $(6-16 \%)[13,39]$. Analyses for men and women separately showed that distal radius/ulna fractures were most common in women (21.8-38.7\%), whereas hand (19.7\%) [19], and ankle fractures [40] were most common in men. In three studies [29, 30, 34], fractures were classified according to Center et al. [6]. Hip fractures were present in $1-8 \%$ of patients, major fractures in $13-33 \%$, minor fractures in $58-79 \%$, and finger or toe fractures in $1-13 \%$.

\section{Body Mass Index}

Mean body mass index (BMI) was reported in nine studies, ranging from 24 to $29 \mathrm{~kg} / \mathrm{m}^{2}$ (Table 2) [19, 25, 31, 33, 34, 39, 45, 46, 48], and was similar for men and women [30, 34]. According to the World Health Organisation BMI classification, 2-6\% of patients were classified as underweight $\left(<18.50 \mathrm{~kg} / \mathrm{m}^{2}\right), 31-33 \%$ had a normal BMI $(18.50-24.99 \mathrm{~kg} /$ $\mathrm{m} 2), 35-38 \%$ were overweight $\left(25.00-29.99 \mathrm{~kg} / \mathrm{m}^{2}\right)$, and 26-30\% were obese $\left(\geq 30 \mathrm{~kg} / \mathrm{m}^{2}\right)[27,39,46]$. 
Table 2 Reported components of the FLS patients' phenotype

\begin{tabular}{|c|c|c|c|c|c|c|}
\hline \multirow[t]{2}{*}{ Author } & \multirow[t]{2}{*}{ Age (mean) } & \multirow[t]{2}{*}{$\operatorname{Men}(\%)$} & \multicolumn{3}{|c|}{ Fracture location $(\%)$} & \multirow[t]{2}{*}{ BMI (mean) } \\
\hline & & & Hip & Clinical VF & $\mathrm{NV} / \mathrm{NH}$ & \\
\hline \multicolumn{7}{|c|}{$\mathrm{IP}+\mathrm{OP}, \mathrm{F}+\mathrm{M}, 50+$, all $\mathrm{Fx}$} \\
\hline \multicolumn{7}{|l|}{ McLellan [13] } \\
\hline Blonk [19] & 64 & 24 & 9 & 5 & 86 & 27 \\
\hline Eekman [20] & 68 & 22 & & & & \\
\hline Fraser [21] & 70 & 14 & 8 & 10 & 82 & \\
\hline Malgo [22] & 67 & 27 & 9 & 6 & 85 & \\
\hline Naranjo [23] & 71 & 23 & 22 & 6 & 72 & \\
\hline Naranjo [24] & 72 & 22 & 26 & & & \\
\hline Ojeda [25] & 70 & 13 & 19 & 8 & 73 & 29 \\
\hline Woltman [26] & 73 & 21 & 23 & 2 & 75 & \\
\hline Ong [27] & 66 & 17 & & & & \\
\hline Van den Berg [28] & & 20 & & & & \\
\hline Huntjens [29] & 67 & 23 & 6 & & & \\
\hline Bours [30] & & 23 & & & & \\
\hline De Klerk [31] & 67 & 21 & 8 & 13 & 79 & 28 \\
\hline De Klerk [32] & 66 & 22 & & & & \\
\hline Hegeman [33] & 67 & 26 & 11 & 3 & 86 & 25 \\
\hline Wyers [34] & 65 & 28 & 8 & & & 26 \\
\hline Van Helden [35] & 67 & 28 & 13 & 3 & 84 & \\
\hline Range & $64-73$ & $13-28$ & $6-26$ & $2-13$ & $72-86$ & $25-29$ \\
\hline \multicolumn{7}{|c|}{$\mathrm{IP}+\mathrm{OP}, \mathrm{F}+\mathrm{M}, 50+, \mathrm{NVF}$} \\
\hline Gallacher [39] & & 23 & 5 & Excl. & 95 & 24 \\
\hline Howat $[40]$ & & 21 & 13 & Excl. & 87 & \\
\hline Huntjens [42] & 67 & 27 & & Excl. & & \\
\hline Range & 67 & $21-27$ & $5-13$ & Excl. & $87-95$ & 24 \\
\hline \multicolumn{7}{|c|}{$\mathrm{IP}+\mathrm{OP}, \mathrm{F}+\mathrm{M}$, all $\mathrm{Fx}$, various ages } \\
\hline Langridge [37] & 78 & & 28 & & & \\
\hline Ahmed [43] & & 19 & 2 & 3 & 95 & \\
\hline Abbad [44] & 80 & 21 & 45 & & & \\
\hline \multicolumn{7}{|l|}{ Miscellaneous } \\
\hline Van Helden [36] & 67 & 28 & & & & \\
\hline Dumitrescu [38] & 68 & 27 & 17 & 4 & 79 & \\
\hline Gallacher [41] & 66 & 24 & 26 & Excl. & 74 & \\
\hline Premaor [45] & & Excl. & 6 & $<1$ & 94 & 27 \\
\hline Premaor [46] & & Excl. & 10 & $<1$ & 90 & 27 \\
\hline Dehamchia [47] & 67 & 25 & 28 & & & \\
\hline Nassar [48] & 74 & 13 & 51 & Excl. & 49 & 24 \\
\hline Ganda [49] & 65 & 20 & & & & \\
\hline Beringer [50] & 65 & 30 & Excl. & 41 & 59 & \\
\hline Range overall & $64-80$ & $13-30$ & $2-51$ & $<1-41$ & $49-95$ & $24-29$ \\
\hline
\end{tabular}

\section{Bone Mineral Density}

In all 33 studies, bone mineral density (BMD) measurement at the lumbar spine and hip was performed (Table 3 and Fig. 4) [13, 19-50], with additional measurements at the distal radius in one study [33]. Based on the lowest $\mathrm{T}$-score, osteoporosis was diagnosed in $12-54 \%$ of patients in 22 studies [19, 21-24, 26, 28-36, 39, 43-48], osteopenia was diagnosed in $29-55 \%$ of patients in 18 studies [21-24, 29-36, 39, 43-47], and 13-39\% of patients had a normal BMD in 18 studies [21-24, 29-36, 39, 43-47]. Osteoporosis was reported in 14-43\% of women and in $6-28 \%$ of men [13, 28-30, 32, 34, 35]. Osteoporosis was most common in patients with a hip (36-63\%) 


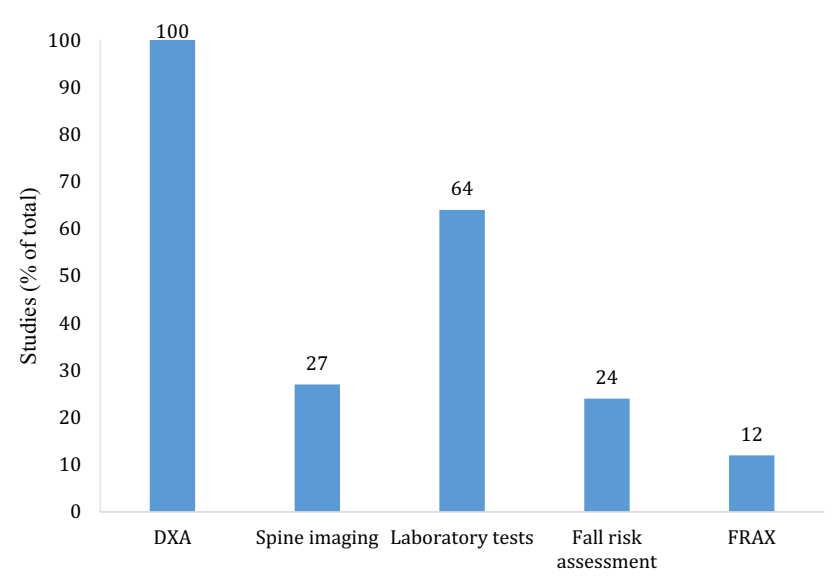

Fig. 4 Percentage of studies reporting assessments for fracture risk evaluation

$[13,19,29,48]$, and vertebral fracture [19], and least in patients with a foot, and clavicle fracture [19]. Classified according to Center et al. [6], osteoporosis was found in $31 \%$ of patients with a minor, in $49 \%$ of patients with a major, and in 58\% of patients with a hip fracture [30]. Osteopenia was found in $49 \%$ of patients with a minor, in $39 \%$ of patients with a major, and in $42 \%$ of patients with a hip fracture [30].

\section{Vertebral Fracture Assessment}

Imaging of the spine was performed using densitometric vertebral fracture assessment (VFA) in four studies [38-40, 48], and X-ray in five (Table 3 and Fig. 4) [19, 28, 31, 33, 44]. Classified according to Genant et al. [51], vertebral fractures (VF) were present in $20-57 \%$ of patients $[31,33,38-40,44,48]$, with VF grade 2 or 3 in $55-73 \%$ of VF patients and $17-31 \%$ of all patients $[38,39,48]$. The prevalence of VF was similar for men (19-24\%) and women $(20-25 \%)$ [39, 40]. VF were present in $30 \%$ of non-vertebral fracture patients aged $>75$ years compared with 23 and $22 \%$ of patients aged 50-64 years and 65-75 years [39]. In contrast, Howat et al. [40] reported higher prevalence rates of VF with increasing age. The prevalence of VF varied by NVF location, with highest prevalence in hip fracture patients for both men (hip fractures $32 \%$ vs. ankle fractures $8 \%$ ) and women (hip fractures $31 \%$ vs. humeral fractures 5\%) $[39,40,48]$. Patients with lumbar spine T-scores in the osteoporotic range were more likely to have VF (42\%) than patients with T-scores in the osteopenic or normal range (20 and $16 \%$ respectively $(p<0.05)$ ) [39]. Similar findings were reported for VF grade 2 or 3 (34 vs. 13 vs. 9\% of patients with osteoporosis, osteopenia, and a normal BMD, respectively $(p<0.0001))$ [39].

\section{Trabecular Bone Score}

Only Nassar et al. [48] reported the trabecular bone score (TBS) in non-vertebral fracture patients at the FLS. Mean TBS was $1.201 \pm 0.113$ and mean TBS was lower in patients with VFs than in those without VFs in VFA $(1.156 \pm 0.108$ vs. $1.227 \pm 0.107, p<0.0001)$.

\section{Laboratory Tests}

Performance of laboratory test to investigate contributors to secondary osteoporosis and metabolic bone disorders (SECOB) was reported in 21 studies (Fig. 4) [13, 19-25, 28-30, 32-34, 37-39, 41, 43, 47, 50]. Two studies reported contributors to SECOB including vitamin D deficiency $(<50 \mathrm{nmol} / \mathrm{L})$, ranging from 50 to $70 \%$ $[30,38]$, and three studies reported contributors to SECOB excluding vitamin D deficiency, ranging from 3 to $28 \%$ (Table 3) [22, 30, 32]. The prevalence rates of contributors to SECOB were similar for men and women (28 vs. $26 \%$ ) [30], were higher in patients with osteoporosis (33-35\%) compared to $27-29 \%$ and $10-18 \%$ of those with osteopenia and a normal BMD, respectively [22,30] and were also higher in patients with more severe fractures according to Center (23).

Four studies [21, 38, 41, 50] reported mean vitamin D, ranging from 44 to $68 \mathrm{nmol} / \mathrm{L}$ and seven studies $[22,30,33,38,41,43,50]$ reported vitamin $\mathrm{D}<50 \mathrm{nmol} / \mathrm{L}$, ranging from 42 to $72 \%$ (Table 3). Mean vitamin D was lower in hip than in non-hip fracture patients (35 vs. 48 respectively, $p=.019$ ) [41]. The prevalence of vitamin $\mathrm{D}<50 \mathrm{nmol} / \mathrm{L}$ was similar for men and women $(62 \mathrm{vs}$. $53 \%$ respectively, $p=.478$ ) [50], for patients aged $<75$ years and those aged $\geq 75$ years (53 vs. $61 \%$ respectively, $p=.522$ ) [50], and for patients with osteoporosis, osteopenia and a normal BMD (42 vs. 43 vs. $42 \%$ respectively) [22].

\section{Daily Calcium Intake}

Only three studies reported mean daily calcium intake $[19,33,38]$, ranging from 759 to $912 \mathrm{mg} /$ day, and two studies reported daily calcium intake $<1200 \mathrm{mg} /$ day, ranging from 86 to $91 \%$ of patients [30, 38]. Daily calcium intake $<1200 \mathrm{mg} /$ day was similar for men and women, age decades, fracture location according to Center et al. [6], and patients with a normal BMD, osteopenia, and osteoporosis [30].

\section{Fracture Risk Assessment Tools}

FRAX score for major fractures was $8-13 \%$ in four studies, and for hip fractures $3-7 \%$ in four studies [23-25, 28]. In 
L. Vranken et al.: The Phenotype of Patients with a Recent Fracture

255

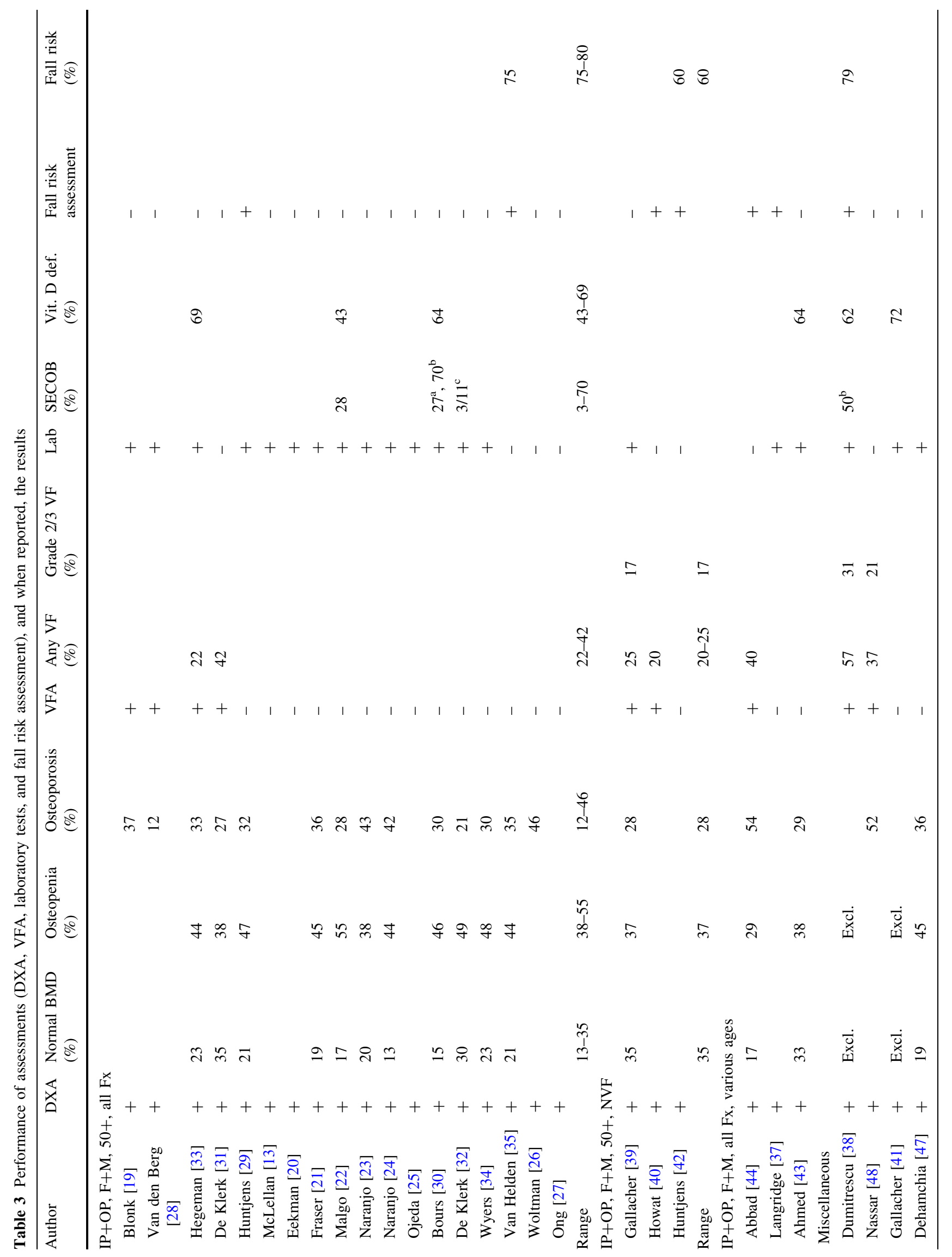

Springer 


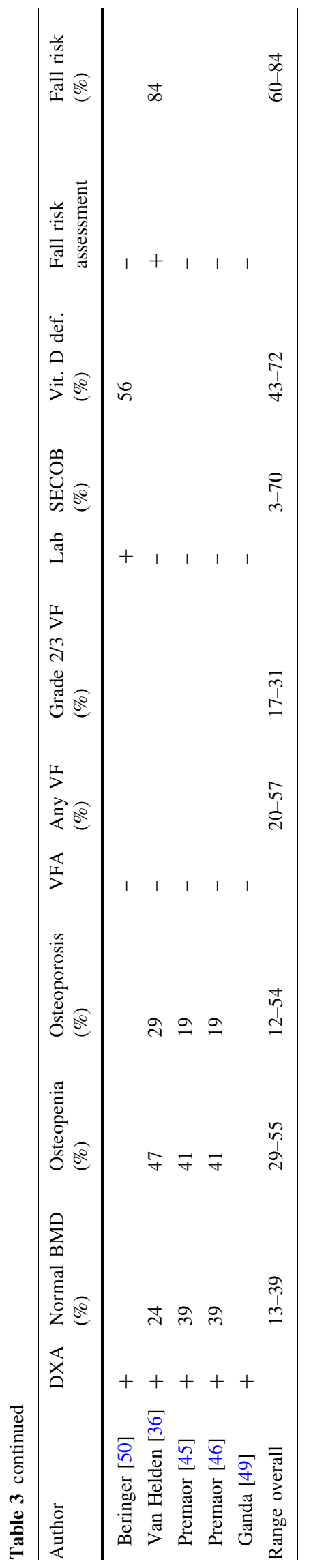

$46-49 \%$ of patients, FRAX score for hip fractures was $>3 \%[23,24]$.

\section{Fall-risk Assessment}

Fall-risk assessment was reported to be performed in eight studies (Fig. 4) [29, 35-38, 40, 42, 44]. Only four studies $[35,36,38,42]$ reported prevalence rates of fall-risk factors, with at least one fall-risk factor in $60-84 \%$ of patients (Table 3). All fall-risk factors were more frequently reported in women, with the exception of impaired vision, which was found in $25 \%$ of women and $31 \%$ of men [35].

\section{Discussion}

This survey aimed to describe the bone- and fall-related components of the phenotype of patients attending the FLS based on 33 FLS related papers. The reported phenotypic characteristics varied widely among the various publications with regard to the mean age, proportion of men, and fracture location. In addition, the proportion of patients with osteoporosis, prevalent vertebral fractures, newly diagnosed contributors to secondary osteoporosis and metabolic bone disease, and proportion of patients with fall-related risk factors varied substantially across studies. Although, there is a great heterogeneity in components of the phenotype, the prevalence rates of these components were high.

The heterogeneity of reported phenotypes of FLS patients can be explained by several aspects. Firstly, the variability in the FLS patients phenotype can be explained by differences in patient selection and FLS attendance. Positioning papers on secondary fracture prevention by the ASBMR, IOF, and EULAR/EFORT [11, 15, 18], recommended that all patients aged 50 years or older with a recent fracture should have their risk for subsequent fractures evaluated at the FLS. In three out of four studies, this recommendation was implemented successfully. Nine studies selected another group of patient for evaluation at the FLS based on different selection criteria (only inpatients, only women, only patients aged 75 years or older, only NVF patients). Additionally, various combinations of selection criteria were used, such as only low-trauma or fragility fracture patients, or excluded patients with pathological fractures. Further, FLS attendance rates ranged from 20 to $89 \%$. This indicates that achieving adequate FLS patient selection and attendance is a major challenge and often hampered by logistic obstacles. It has been shown that FLS care with a central coordinator (often a specialised nurse) is the most appropriate clinical organization model for secondary fracture prevention $[11,15,18]$. Although capturing all fracture patients is the ultimate goal, it has been suggested that an FLS may 
initially focus on a subgroup [15]. Once secondary fracture prevention for these patients has been well-established, the scope of the FLS should be expended to eventually include all fracture patients. In addition, other approaches, such as an orthogeriatric service, may have been established in hospitals to systematically optimise care of hip fracture patients, including components covered by a FLS [52]. This type of service of course alters the phenotype of the patients attending the FLS. In our literature survey, all but six studies focussed on all patients regardless of their fracture location. Of these six studies, one study [50] excluded hip fractures.

Second, as recommended in the positioning papers, risk evaluation should include dual-energy X-ray absorptiometry (DXA), and vertebral fracture assessment (VFA), and on indication, laboratory tests, and fall risk assessments [18]. DXA evaluation was performed in all studies, imaging of the spine in nine studies, laboratory tests in 21 studies, and fall risk evaluation in eight studies. Since these assessments often have to be justified through local business cases supported by solid health economic analysis, which are currently lacking, implementation of these assessments is not always feasible. Hence, the reported outcomes of the various bone- and fall-related components of FLS patients may be influenced not only by patients selection and attendance rates, but also by the possibility to perform additional assessments in all FLS patients [52].

Based on these results in literature, it is difficult to describe the full spectrum of bone and fall risks in patients attending the FLS. In the context of fracture prevention, knowledge of the presence and combinations of the risk factors will guide the need for evaluation and treatment. In this literature survey of FLS, we found a high variability in patient selection and fracture risk evaluation. In order to specify the bone- and fall-related phenotypes at the FLS, systematic studies on the presence and combinations of these risks are needed.

Open Access This article is distributed under the terms of the Creative Commons Attribution 4.0 International License (http://crea tivecommons.org/licenses/by/4.0/), which permits unrestricted use, distribution, and reproduction in any medium, provided you give appropriate credit to the original author(s) and the source, provide a link to the Creative Commons license, and indicate if changes were made.

\section{References}

1. Kanis JA, Johnell O, Oden A et al (2000) Long-term risk of osteoporotic fracture in malmö. Osteoporos Int 11:669-674. doi:10.1007/s001980070064

2. van Staa TP, Dennison EM, Leufkens HGM, Cooper C (2001) Epidemiology of fractures in England and Wales. Bone 29:517-522. doi:10.1016/S8756-3282(01)00614-7
3. Hernlund E, Svedbom A, Ivergård M et al (2013) Osteoporosis in the European Union: medical management, epidemiology and economic burden. Arch Osteoporos 8:136. doi:10.1007/s11657013-0136-1

4. Klotzbuecher CM, Ross PD, Landsman PB et al (2010) Patients with prior fractures have an increased risk of future fractures: a summary of the literature and statistical synthesis. J Bone Miner Res 15:721-739. doi:10.1359/jbmr.2000.15.4.721

5. Kanis JA, Johnell O, De Laet C et al (2004) A meta-analysis of previous fracture and subsequent fracture risk. Bone 35:375-382. doi:10.1016/j.bone.2004.03.024

6. Center JR, Nguyen TV, Schneider D et al (1999) Mortality after all major types of osteoporotic fracture in men and women: an observational study. The Lancet 353:878-882. doi:10.1016/ S0140-6736(98)09075-8

7. Center JR, Bliuc D, Nguyen TV, Eisman JA (2007) Risk of subsequent fracture after low-trauma fracture in men and women. JAMA 297:387-394. doi:10.1001/jama.297.4.387

8. Werkgroep CBO (2011) Richtlijn osteoporose en fractuurpreventie, derde herziening [Dutch]. CBO, Utrecht

9. Compston J, Bowring C, Cooper A et al (2013) Diagnosis and management of osteoporosis in postmenopausal women and older men in the UK: National Osteoporosis Guideline Group (NOGG) update 2013. Maturitas 75:392-396. doi:10.1016/j.maturitas. 2013.05.013

10. Cosman F, de Beur SJ, LeBoff MS et al (2014) Clinician's guide to prevention and treatment of osteoporosis. Osteoporos Int 25:2359-2381. doi:10.1007/s00198-014-2794-2

11. Lems WF, Dreinhöfer KE, Bischoff-Ferrari H et al (2016) EULAR/EFORT recommendations for management of patients older than 50 years with a fragility fracture and prevention of subsequent fractures. Ann Rheum Dis annrheumdis. doi:10.1136/ annrheumdis-2016-210289

12. Giangregorio L, Papaioannou A, Cranney A et al (2006) Fragility fractures and the osteoporosis care gap: an international phenomenon. Semin Arthritis Rheum 35:293-305. doi:10.1016/j. semarthrit.2005.11.001

13. McLellan AR, Gallacher SJ, Fraser M, McQuillian C (2003) The fracture liaison service: success of a program for the evaluation and management of patients with osteoporotic fracture. Osteoporos Int 14:1028-1034. doi:10.1007/s00198-003-1507-z

14. van den Bergh JP, van Geel TA, Geusens PP (2012) Osteoporosis, frailty and fracture: implications for case finding and therapy. Nat Rev Rheumatol 8:163-172. doi:10.1038/nrrheum.2011.217

15. IOF Fracture Working Group, Åkesson K, Marsh D et al (2013) Capture the fracture: a best practice framework and global campaign to break the fragility fracture cycle. Osteoporos Int 24:2135-2152. doi:10.1007/s00198-013-2348-z

16. IOF Fracture Working Group, EXCO, Javaid MK et al (2015) Effective secondary fracture prevention: implementation of a global benchmarking of clinical quality using the IOF capture the fracture ${ }^{\circledR}$ best practice framework tool. Osteoporos Int 26:2573-2578. doi:10.1007/s00198-015-3192-0

17. IOF CSA Fracture Working Group, Marsh D, Åkesson $\mathrm{K}$ et al (2011) Coordinator-based systems for secondary prevention in fragility fracture patients. Osteoporos Int 22:2051-2065. doi:10. 1007/s00198-011-1642-x

18. Eisman JA, Bogoch ER, Dell R et al (2012) Making the first fracture the last fracture: ASBMR task force report on secondary fracture prevention. J Bone Miner Res 27:2039-2046. doi:10. 1002/jbmr. 1698

19. Blonk MC, Erdtsieck RJ, Wernekinck MGA, Schoon EJ (2007) The fracture and osteoporosis clinic: 1-year results and 3-month compliance. Bone 40:1643-1649. doi:10.1016/j.bone.2007.01.023

20. Eekman DA, van Helden SH, Huisman AM et al (2013) Optimizing fracture prevention: the fracture liaison service, an 
observational study. Osteoporos Int 25:701-709. doi:10.1007/ s00198-013-2481-8

21. Fraser S, Wong PKK (2016) Secondary fracture prevention needs to happen in the country too: the first two and a half years of the Coffs Fracture Prevention Clinic. Aust J Rural Health. doi:10. 1111/ajr.12291

22. Malgo F, Appelman-Dijkstra NM, Termaat MF et al (2016) High prevalence of secondary factors for bone fragility in patients with a recent fracture independently of BMD. Arch Osteoporos 11:12. doi:10.1007/s11657-016-0258-3

23. Naranjo A, Ojeda-Bruno S, Bilbao Cantarero A et al (2014) Results of a model of secondary prevention for osteoporotic fracture coordinated by rheumatology and focused on the nurse and primary care physicians. Reumatología Clínica (English Edition) 10:299-303. doi:10.1016/j.reumae.2014.03.004

24. Naranjo A, Ojeda-Bruno S, Bilbao-Cantarero A et al (2015) Twoyear adherence to treatment and associated factors in a fracture liaison service in Spain. Osteoporos Int 26:2579-2585. doi:10. 1007/s00198-015-3185-z

25. Ojeda-Bruno S, Naranjo A, Francisco-Hernández F et al (2010) Secondary prevention program for osteoporotic fractures and long-term adherence to bisphosphonates. Osteoporos Int 22:1821-1828. doi:10.1007/s00198-010-1414-z

26. Woltman K, den Hoed PT (2010) Osteoporosis in patients with a low-energy fracture: 3 years of screening in an osteoporosis outpatient clinic. J Trauma 69:169-173. doi:10.1097/TA. 0b013e3181ca081f

27. Ong T, Sahota O, Tan W, Marshall L (2014) A United Kingdom perspective on the relationship between body mass index (BMI) and bone health: a cross sectional analysis of data from the Nottingham Fracture Liaison Service. Bone 59:207-210. doi:10. 1016/j.bone.2013.11.024

28. van den Berg P, van Haard P, van den Bergh J et al (2014) First quantification of Calcium intake from calcium-dense dairy products in Dutch fracture patients (the delft cohort study). Nutrients 6:2404-2418. doi:10.3390/nu6062404

29. Huntjens KMB, van Geel TACM, Blonk MC et al (2010) Implementation of osteoporosis guidelines: a survey of five large fracture liaison services in the Netherlands. Osteoporos Int 22:2129-2135. doi:10.1007/s00198-010-1442-8

30. Bours SPG, van Geel TACM, Geusens PPMM et al (2011) Contributors to secondary osteoporosis and metabolic bone diseases in patients presenting with a clinical fracture. J Clin Endocrinol Metab 96:1360-1367. doi:10.1210/jc.2010-2135

31. de Klerk G, Hegeman JH, Bronkhorst P et al (2012) The (a)symptomatic vertebral fracture: a frequently discovered entity with clinical relevance in fracture patients screened on osteoporosis. Geriatr Orthop Surg Rehabil 3:74-78. doi:10.1177/ 2151458512449833

32. de Klerk G, Hegeman JH, van der Velde D et al (2013) The value of laboratory tests in diagnosing secondary osteoporosis at a fracture and osteoporosis outpatient clinic. Geriatr Orthop Surg Rehabil 4:53-57. doi:10.1177/2151458513501176

33. Hegeman JH, Willemsen G, van Nieuwpoort J et al (2005) Effective case-finding of osteoporosis in a fracture and osteoporosis clinic in Groningen: an analysis of the first 100 patients. Aktuelle Traumatol 35:34-39. doi:10.1055/s-2005-837557

34. Wyers CE, Vranken L, van der Velde RY et al (2014) Cardiovascular risk factor analysis in patients with a recent clinical fracture at the fracture liaison service. Biomed Res Int 2014:1-8. doi:10.1155/2014/710945

35. van Helden S, van Geel AC, Geusens PP et al (2008) Bone and fall-related fracture risks in women and men with a recent clinical fracture. J Bone Joint Surg-Am 90:241-248. doi:10.2106/JBJS.G. 00150
36. van Helden S, Wyers CE, Dagnelie PC et al (2007) Risk of falling in patients with a recent fracture. BMC Musculoskelet Disord 8:348. doi:10.1186/1471-2474-8-55

37. Langridge CR, McQuillian C, Watson WS et al (2007) Refracture following fracture liaison service assessment illustrates the requirement for integrated falls and fracture services. Calcif Tissue Int 81:85-91. doi:10.1007/s00223-007-9042-0

38. Dumitrescu B, van Helden S, ten Broeke R et al (2008) Evaluation of patients with a recent clinical fracture and osteoporosis, a multidisciplinary approach. BMC Musculoskelet Disord 9:241. doi:10.1186/1471-2474-9-109

39. Gallacher SJ, Gallagher AP, McQuillian C et al (2006) The prevalence of vertebral fracture amongst patients presenting with non-vertebral fractures. Osteoporos Int 18:185-192. doi:10.1007/ s00198-006-0211-1

40. Howat I, Carty D, Harrison J et al (2007) Vertebral fracture assessment in patients presenting with incident nonvertebral fractures. Clin Endocrinol 67:923-930. doi:10.1111/j.1365-2265. 2007.02988.x

41. Gallacher SJ, McQuillian C, Harkness M et al (2005) Prevalence of vitamin D inadequacy in Scottish adults with non-vertebral fragility fract. Curr Med Res Opin 21:1355-1361. doi:10.1185/ 030079905X59148

42. Huntjens KM, van Geel TA, van Helden S et al (2013) The role of the combination of bone and fall related risk factors on shortterm subsequent fracture risk and mortality. BMC Musculoskelet Disord 14:721. doi:10.1186/1471-2474-14-121

43. Ahmed M, Durcan L, Beirne JO et al (2012) Fracture liaison service in a non-regional orthopaedic clinic-a cost-effective service. Ir Med J 105:26-27

44. Abbad N, Lemeunier L, Chantelot C et al (2016) Secondary prevention program for osteoporotic fractures at Lille University Hospital. La Presse Méd 45:375-377. doi:10.1016/j.lpm.2015.11. 007

45. Premaor MO, Pilbrow L, Tonkin C et al (2009) Low rates of treatment in postmenopausal women with a history of low trauma fractures: results of audit in a Fracture Liaison Service. QJM 103:33-40. doi:10.1093/qjmed/hcp154

46. Premaor MO, Pilbrow L, Tonkin C et al (2009) Obesity and fractures in postmenopausal women. $\mathrm{J}$ Bone Miner Res 25:292-297. doi:10.1359/jbmr.091004

47. Dehamchia-Rehailia N, Ursu D, Henry-Desailly I et al (2014) Secondary prevention of osteoporotic fractures: evaluation of the Amiens University Hospital's fracture liaison service between January 2010 and December 2011. Osteoporos Int 25:2409-2416. doi:10.1007/s00198-014-2774-6

48. Nassar K, Paternotte S, Kolta S et al (2013) Added value of trabecular bone score over bone mineral density for identification of vertebral fractures in patients with areal bone mineral density in the non-osteoporotic range. Osteoporos Int 25:243-249. doi:10.1007/s00198-013-2502-7

49. Ganda K, Schaffer A, Seibel MJ (2014) Predictors of re-fracture amongst patients managed within a secondary fracture prevention program: a 7-year prospective study. Osteoporos Int 26:543-551. doi:10.1007/s00198-014-2880-5

50. Beringer T, Heyburn G, Finch $M$ et al (2005) Prevalence of vitamin D inadequacy in belfast following fragility fracture. Curr Med Res Opin 22:101-105. doi:10.1185/030079906X80332

51. Genant HK, Wu CY, van Kuijk C, Nevitt MC (1993) Vertebral fracture assessment using a semiquantitative technique. J Bone Miner Res 8:1137-1148. doi:10.1002/jbmr.5650080915

52. Harvey NCW, McCloskey EV, Mitchell PJ et al (2017) Mind the (treatment) gap: a global perspective on current and future strategies for prevention of fragility fractures. Osteoporos Int 24:1-23. doi:10.1007/s00198-016-3894-y 